\title{
A AGRICULTURA A PARTIR DO NEOLIBERALISMO: FINANCEIRIZAÇÃO, PODER CORPORATIVO E AS AMEAÇAS À SOBERANIA ALIMENTAR
}

\section{LA AGRICULTURA A PARTIR DEL NEOLIBERALISMO: FINANCERIZACIÓN, PODER CORPORATIVO E LAS AMENAZAS A LA SOBERANIA ALIMENTÁRIA}

\begin{abstract}
AGRICULTURE FROM NEOLIBERALISM: FINANCIALIZATION, CORPORATE POWER AND THREATS TO FOOD SOVEREIGNTY
\end{abstract}

Yamila Goldfarb ${ }^{1}$

RESUMO: O presente artigo foi elaborado a partir da fala realizada na mesa redonda "Soberania Alimentar, Biotecnologia e Monopólio" do seminário Terra, Alimento e Liberdade: o que você alimenta quando se alimenta?, realizado no Departamento de Geografia da Universidade de São Paulo em junho de 2013. O que busco expor neste artigo é um olhar sobre o momento atual em que vivemos a partir da noção de Regime Alimentar. Essa noção deve ser entendida como a forma em que se dão a produção, a circulação, a comercialização e o consumo dos alimentos no mundo. $O$ objetivo é contribuir na elucidação de algumas das transformações ocorridas no campo do Brasil a partir da década de 1970, por meio da análise do estabelecimento do que chamamos Regime Alimentar Corporativo. Uma das hipóteses averiguadas foi a de que com o advento do neoliberalismo houve a consolidação e o aprofundamento da hegemonia das corporações do setor agroalimentar, bem como uma transformação no padrão alimentar, o que acarretou maior ameaça à soberania alimentar.

Palavras-chave: Cargill; corporações; Regime Alimentar Corporativo; soja; monopólio.

RESUMEN: Este artículo fue preparado a partir de las conversaciones mantenidas en la mesa redonda "Soberanía Alimentaria, Biotecnología y Monopolio" del seminario Tierra, Alimentación y Libertad: ¿lo que uno alimenta al alimentarse?, realizado en el Departamento de Geografía de la Universidad de São Paulo en junio de 2013. Lo que me propongo a hacer es tratar de exponer en este artículo una mirada hacia el momento actual en el que vivimos a partir de la noción de Regimen Alimentário. Esta noción se debe entender como la forma en la que se da la producción, la circulación, la comercialización y el consumo de alimentos en el mundo. El objetivo es contribuir al esclarecimiento de algunos de los cambios que se producen en el campo de Brasil desde la década de 1970, a través del análisis de la creación de lo que llamamos régimen alimentar corporativo. Una de las hipótesis investigadas fue que con el advenimiento del neoliberalismo ocurrió la consolidación y profundización de la hegemonía de las empresas del sector agroalimentario, así como un cambio en el patrón de alimentación que causó gran amenaza para la soberanía alimentaria.

\footnotetext{
${ }^{1}$ Doutora em Geografia pela Universidade de São Paulo. Atou no planejamento territorial rural junto a movimentos sociais do campo e da cidade. Atualmente pesquisa temas relacionados à geopolítica latinoamericana e à soberania alimentar. É autora do livro A luta pela terra entre o campo e a cidade: reforma agrária, movimentos sociais e novas formas de assentamentos, editado pela Annablume. yamilamata@yahoo.com.br
} 
Palavras Clave: Cargill; corporaciones; Regimen Alimentar Corporativo; soja; monopolio.

ABSTRACT: This article was prepared after discussions in the debate "Food Sovereignty, Biotechnology and Monopoly" of the Earth's, Food and Freedom seminar: what do you feed when you eat?, performed in the Department of Geography at the University of São Paulo in June, 2013. What I propose to do is try to expose in this article a look into the present moment in which we live using the notion of Food Regime. This notion is to be understood as the way in which the production, circulation, marketing and consumption of food in the world is given. The objective is to help clarify some of the changes that occur in the field of Brazil since the 1970s, through the analysis of the creation of what we call corporate feeding regime. One hypothesis investigated was that with the advent of neoliberalism consolidation and deepening of the hegemony of food businesses has occurred, as well as a change in eating pattern that caused great threat to food sovereignty.

Key Words: Cargill; corporations; Corporative Food Regime; soy; monopoly.

O presente artigo foi elaborado a partir da fala realizada na mesa redonda "Soberania Alimentar, Biotecnologia e Monopólio" do seminário Terra, Alimento e Liberdade: o que você alimenta quando se alimenta?, realizado no Departamento de Geografia da Universidade de São Paulo em junho de 2013.

O que busco expor neste artigo é um olhar sobre o momento atual em que vivemos a partir da noção de Regime Alimentar. Essa noção deve ser entendida como a forma em que se dão a produção, a circulação, a comercialização e o consumo dos alimentos no mundo. A análise do Regime Alimentar permite compreender o papel da agricultura e da alimentação na construção da economia capitalista mundial. O conceito de Regime Alimentar permite historicizar o sistema alimentar global, problematizar as representações lineares da modernização agrícola, sublinhando o papel fundamental dos alimentos na economia política global (MCMICHAEL, 2009a). Ao optar por essa metodologia, defendo uma abordagem que olha o alimento como algo fundamental no desenvolvimento do sistema capitalista porque não se pode dissociar a produção de valor e a reprodução da força de trabalho na história, da produção, circulação e consumo dos 
A Agricultura a Partir do Neoliberalismo: Financeirização, Poder Corporativo e as Ameaças À Soberania Alimentar, pp. 42-58.

alimentos. Isso nos ajuda a compreender os padrões mundiais de circulação dos alimentos. Em suma, buscamos analisar a questão da alimentação, da produção do alimento, do comércio do alimento de uma forma mais ampla que nos permite captar a dimensão agroalimentar da geopolítica.

Atualmente, esse regime caracteriza-se pelo poder de monopólio exercido por grandes corporações transnacionais que atuam na produção, processamento e comercialização de alimentos, bem como na produção de insumos químicos e biotecnológicos e ainda na oferta de financiamento para o setor. Por isso alguns autores o chamam de Regime Alimentar Corporativo. Em outras palavras, as grandes corporações dominam cadeias inteiras relacionadas aos alimentos e, em muitos casos, possuem braços em outros setores, como mineração ou farmacêutico.

As imagens que seguem nos ajudam a ter um pouco da dimensão que as corporações podem chegar a ter. Na primeira imagem (Figura 1) vemos a amplitude de atuação da Cargill' apenas no Brasil, e na segunda imagem (Figura 2), alguns dos produtos por ela produzidos e comercializados também apenas no Brasil.

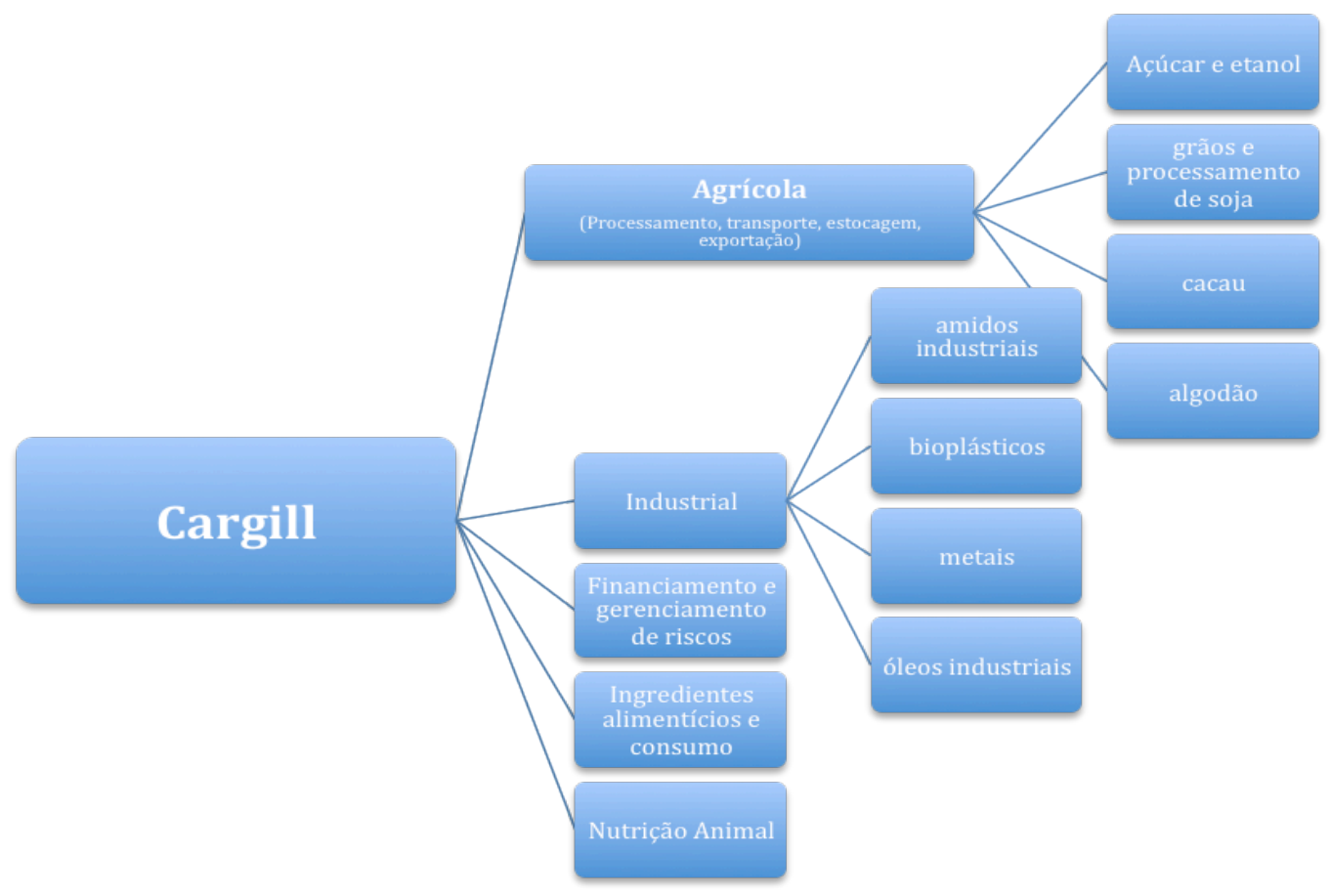

Figura 1

Org: Goldfarb, Y. 


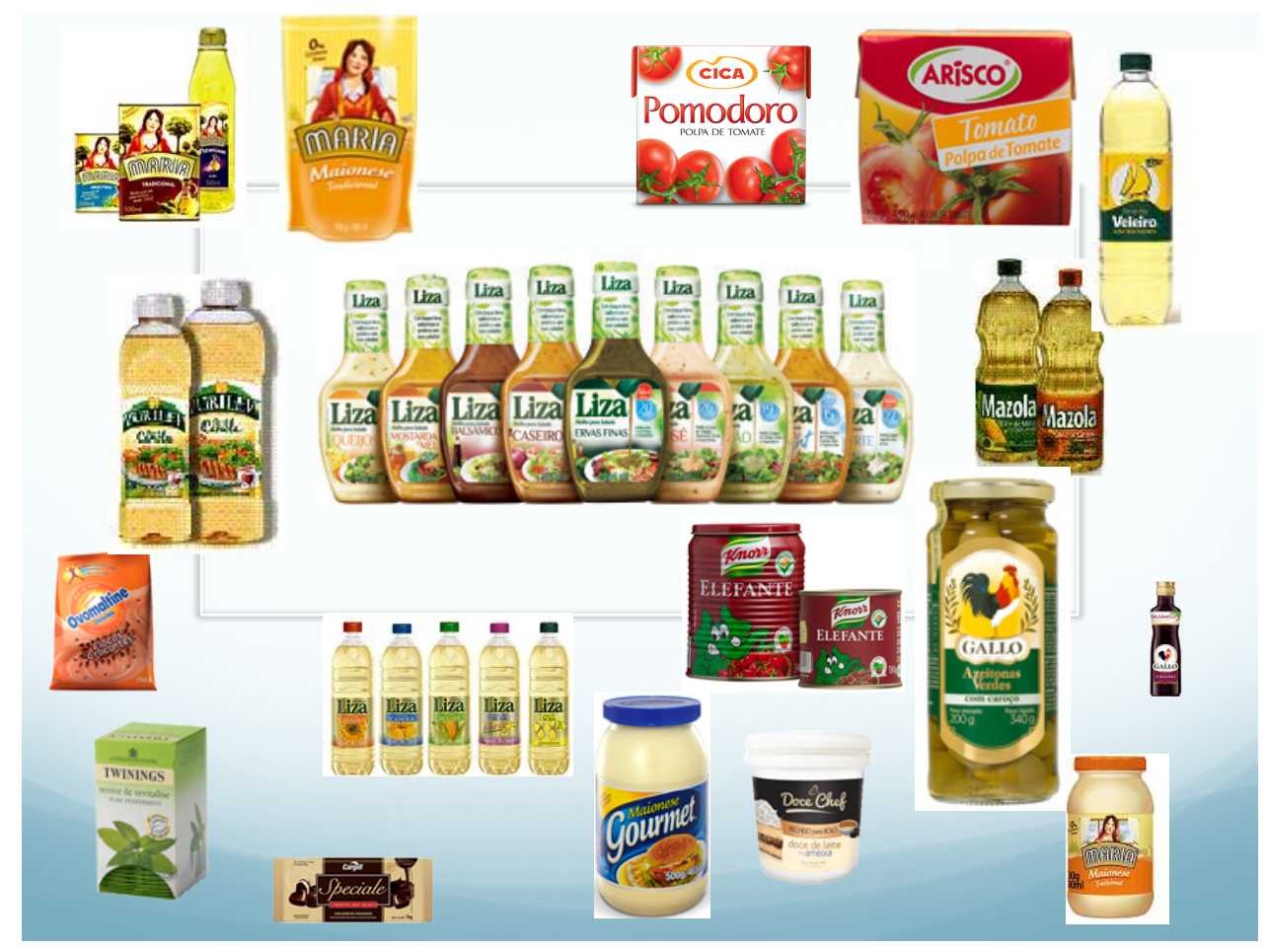

Figura 2

Org. Goldfarb, Y.

Pode-se então olhar para a questão da alimentação no plano da vida cotidiana, já que a alimentação está diretamente relacionada com modos de vida, com a reprodução cultural das populações, mas pode-se ainda olhar para ela no plano dos processos de acumulação de capital no mundo. E pode-se, mais do que isso, relacionar esses dois planos, isto é, analisar como um toca ou atinge o outro.

Pensando nisso, vou expor aqui as transformações que se deram a partir dos anos 1970 e 1980, sem abordar, portanto, os regimes alimentares anteriores.

Os anos 1970 são o marco do que alguns autores como David Harvey colocam como retomada de poder pelas elites nos países que, com o pósGrande Guerra, tinham adotado medidas regulatórias, de muita presença estatal, o que limitava o ganho das elites: as chamadas medidas keynesianas. Vejamos: 
A Agricultura a Partir do Neoliberalismo: Financeirização, Poder Corporativo e as Ameaças À Soberania Alimentar, pp. 42-58.

Os Estados deveriam concentrar-se no pleno emprego, no crescimento econômico e no bem-estar de seus cidadãos. O poder do Estado deveria ser livremente distribuído ao lado dos processos de mercado - ou, se necessário, intervindo ou mesmo substituindo tais processos. Para alcançar esses fins, políticas fiscais e monetárias em geral caracterizadas como "keynesianas" foram implantadas extensamente para suavizar os ciclos de negócio e assegurar um nível de emprego razoavelmente pleno. Os Estados intervieram ativamente na política industrial e passaram a estabelecer padrões para o salário social, construindo uma variedade de sistemas de bem-estar (saúde, educação etc). Havia intervenção pública para a manutenção de uma nutrição mínima por meio de programas de alimentação materna e infantil e da criação de refeitórios para operários. Diversos esforços foram feitos para evitar a fome da Depressão dos anos 1930. É nesse momento que surge o que mais tarde seria a FAO (Food and Agriculture Organization). A FAO, naquele momento, gerenciava a Comissão Mundial de Alimentos que, segundo Friedmann (2005, p. 2),

[...] teria se tornado componente chave de uma ONU forte, se o projeto não tivesse sucumbido às disputas de poder relacionadas com a Guerra Fria e a descolonização.

O planejamento liderado pelo Estado e, em alguns casos, a posse pelo Estado de alguns setores-chave (carvão, aço, automóveis) não foram incomuns. O que o projeto neoliberal pretendia era desvencilhar o capital dessas restrições.

Houve ampliação de gastos públicos e a criação do Estado de bemestar social. Isso, somado às intervenções ativas do Estado na economia e ao planejamento do desenvolvimento, caminhou lado a lado com taxas de crescimento relativamente elevadas.

Porém, perto dos anos 1960, havia-se gerado uma crise de acumulação e o desemprego e a inflação cresciam e criaram uma fase de estagflação que perduraria ao longo dos anos 1970. As receitas provenientes dos impostos caíam, mas os gastos sociais aumentavam acentuadamente. A porosidade das fronteiras dos Estados com relação aos 
fluxos de capital pressionava o sistema de taxas de câmbio fixas. O dólar dos Estados Unidos tinha inundado o mundo e escapado ao controle daquele país, sendo depositado em bancos europeus. Por causa disso, as taxas de câmbio fixas foram abandonadas em 1971. O ouro não mais poderia funcionar como base metálica da moeda internacional; as taxas de juros passaram a ser flutuantes e as tentativas de controlar a flutuação logo foram abandonadas.

O resultado foi a polarização do debate entre aqueles que apoiavam a social-democracia e o planejamento central, de um lado, e aqueles que pretendiam liberar o poder corporativo e dos negócios e restabelecer as liberdades de mercado, do outro. Em meados dos anos 1970, os interesses desse segundo grupo passaram à frente. A neoliberalização foi a maneira de restaurar as condições de acumulação do capital. Mais tarde, nos anos 1990, isso convergiria no que se chamou Consenso de Washington. Ou seja, a estratégia para essa retomada de poder foi a implementação, tanto no campo ideológico como econômico, do neoliberalismo.

A partir daí, desmembram-se diversas implicações para a questão da alimentação, da agricultura e consequentemente para o meio ambiente. Vamos falar um pouco delas:

A redução da intervenção do Estado na produção e comercialização de alimentos vai ajudar a conformar o Regime Alimentar Corporativo. O atrelamento da produção de alimentos ao sistema financeiro tornou-se maior na medida em que os governos reduziram a sua participação na regulação do mercado e eliminaram as empresas estatais responsáveis pela administração de estoques reguladores. Burch e Lawrence ${ }^{2}$ (2009 apud MCMICHAEL, 2009a, p. 158) afirmam que o que há de novo no Regime Alimentar Corporativo é o papel

[...] desempenhado por uma série de instituições e instrumentos financeiros que possuem a capacidade de voltar a organizar as distintas etapas da cadeia de produtos agroalimentares e de modificar os termos e condições em que os outros atores da cadeia podem operar.

\footnotetext{
${ }^{2}$ BURCH, D.; LAWRENCE, G. Towards a third food regime: behind the transformation.
}

Agriculture and Human Values, Nova York, n. 26, n. 4, pp. 281-295, dez. 2009. 
Segundo McMichael (2009b), as grandes corporações submetem a produção a uma lógica especulativa e buscam tirar proveito dos preços em alta, agravando as crises de abastecimento alimentar. Elas controlam os preços que são pagos aos produtores e os preços que são cobrados no mercado. Basta ver a capacidade que as corporações possuem de armazenar milhões de toneladas de grãos, segundo a Companhia Nacional de Abastecimento. Mas não é apenas o controle da compra e venda de determinadas commodities que caracteriza o poderio das corporações do setor agroalimentar. A partir da década de 1970, essas corporações passam a impulsionar, em nível mundial, um processo de transição tecnológica à biotecnologia e, em especial, em direção à engenharia genética. Novos pacotes tecnológicos que demandam alto investimento de capital por hectare, com alto uso de insumos externos e baixo uso de mão de obra, são usados para que, por meio de monoculturas, se possam obter produtos uniformes adequados à cadeia de processamento industrial. Evidentemente, quem vende esses pacotes são as mesma corporações que irão processar o produto.

A retirada do Estado como financiador e articulador do processo de modernização conservadora do campo a partir da adoção das políticas neoliberais e da crise fiscal do Estado foi um fator determinante para a financeirização da agricultura no Brasil. A crise fiscal era marcada por dívida pública (tanto interna como externa) elevada e uma poupança pública sempre negativa (diferença entre receita e despesa corrente).

[...] ocorreu um processo rápido e algo caótico de demolição dos aparatos de Estado constituídos desde 1930 em distintas instâncias da política agrícola: as instituições por produto e os subsistemas de regulação funcional do setor rural (MAZZALI, 2000, p. 34).

As instituições por produto (IAA - Instituto do Açúcar e do Álcool, IBC - Instituto Brasileiro do Café, Monopólio do Trigo) foram extintas e seus sistemas de regulação comercial e produtiva foram transferidos a outros organismos ou simplesmente extintos. Ao mesmo tempo, com relação às 
instituições estratégicas ligadas ao financiamento (SNCR - Sistema Nacional de Crédito Rural, PGPM - Política de Garantia de Preços Mínimos) e ao apoio tecnológico (Embrapa, Embrater), Delgado (1985, p. 16) ressalta que

[...] as mudanças havidas apontam na direção de uma substancial redução dos recursos orçamentários do governo federal, reduzidos a valores entre $1 / 3$ e $1 / 2$ daquilo que foram em 1987 e a valores ainda bem menores quando confrontados com indicadores do final dos 70.

Se considerarmos que o Estado situava-se no centro do padrão de desenvolvimento agroindustrial, inaugurado em meados dos anos 1960, como patrocinador, legitimador e financiador das articulações entre os diferentes agentes econômicos, a desarticulação do seu aparato de regulação, sem que se defina um novo papel, representou uma desorganização dos interesses [de determinados] setores rurais e, mais significativamente, uma reorientação no comportamento desse agente (MAZZALI, 2000).

A partir dos anos 1980, esse padrão de desenvolvimento tecnológico, o estilo de inserção da agricultura no mercado internacional e o perfil de intervenção estatal sofreram grande modificações. Marca o novo período, segundo Mazzali, a ampliação considerável do campo de ação por parte dos diferentes capitais com interesses na atividade agroindustrial. Com a diminuição do papel interventor e articulador do Estado, abriu-se espaço para articulações pensadas a partir de setores privados. Fica claro aqui o processo de transição para o Regime Alimentar Corporativo.

Se tomarmos essa interpretação como base, podemos dizer que o aumento de poder ou o maior grau de autonomia e de interferência das instituições privadas são resultado da "retirada" do Estado de seu papel interventor e regulador. Mas é preciso ter um cuidado. Devemos considerar que o que ocorre com o Estado não é algo ao acaso, mas sim algo que, em parte, foi também articulado, negociado e posto em prática, justamente por instituições privadas e interesses corporativos. O cuidado deve existir para não se "naturalizar" a maior atuação das grandes empresas como se isso fosse apenas uma reação a um contexto externo a elas, quando na 
realidade sabemos que essa separação tão clara entre setores privados e Estado não existe de fato.

Outro aspecto muito importante dessa reconfiguração é a transformação das articulações entre fornecedores, distribuidores e clientes e o fato de que houve a implementação por parte da agroindústria de novos mecanismos de financiamento e de comercialização da safra, ocupando um espaço deixado pelo Estado. A indústria passou a se constituir como importante agente financeiro no campo. Isso é chave para o estabelecimento do Regime Alimentar Corporativo. Vejamos:

A partir de 1979, com a crise fiscal do Estado verificou-se além do fim do subsídio ao crédito agrícola uma contínua redução da disponibilidades de recursos oficiais. Ademais, a prometida adoção de uma política mais ativa de garantia de preços mínimos não se efetivou, uma vez que

observou-se ao longo da década uma redução ou quase
eliminação dos recursos do EGF (Empréstimo do Governo
Federal) para a soja (movimento que se verificou para todos
os produtores agrícolas), como reflexo inequívoco do
agravamento da crise fiscal brasileira (CASTRO, 1993, p. 86).

Os mecanismos de financiamento que passaram a ser utilizados foram os ACC - Antecipação de Contrato de Câmbio e as compras por meio de trocas por fertilizantes e sementes. Essas estratégias foram formas de garantir a disponibilidade de grãos por parte das agroindústrias. Cargill e Quintella passaram a ser importantes viabilizadoras das lavouras de soja da Região Centro-Oeste por meio da compra antecipada de safra, com a entrega de insumos para pagamento futuro em grãos.

A mesma estratégia passou a ser utilizada pelos produtores para adquirir bens de maior valor como tratores. Um exemplo se deu entre a Maxion, empresa fabricante de colheitadeiras e tratores, e a Cargill. Elas criaram um sistema de troca de seus produtos no qual a Cargill adquiria os grãos para venda futura e os recursos eram repassados a Maxion, que entregava o bem ao produtor agrícola. Como coloca Mazzali, isso exigia 
uma complexa engenharia financeira. Os produtores passaram a comprar um trator, por exemplo, com certificados futuros de soja. O revendedor de tratores entregava o certificado ao banco e recebia dinheiro. Mas o banco, por sua vez, repassava esses certificados para uma trading e recebia títulos emitidos por essas empresas exportadoras (MAZZALI, 2000).

As dificuldades de acesso ao crédito não apenas estimularam as vendas antecipadas como criaram todo um mercado de especulação sobre as dificuldades do produtor. Inúmeras formas de agiotagem a juros elevados foram surgindo, realizadas por agentes não ligados à produção agrícola, tais como corretores de imóveis, médicos etc., além do financiamento realizado por cerealistas, vendedores de insumos e comerciantes ligados à produção agrícola. Em 1994, o mecanismo de compra antecipada ganha um sistema mais "sofisticado" com a criação da CPR - Cédula do Produto Rural, que podia ser comercializada na BM\&F.

Principais pontos da cartilha neoliberal, as privatizações e a liberalização do mercado possibilitaram a expropriação de ativos públicos e a sua entrega ao mercado para que o capital sobreacumulado se encarregasse de utilizá-los. Como coloca Harvey (2011), esse movimento desencadeou a descoberta de inúmeras arenas em que se pudessem executar privatizações. Acrescentamos aqui o caso das sementes, da cultura e do saberes tradicionais como exemplos.

Entendemos que a lógica e os interesses do capital financeiro não apenas permeiam o capital produtivo, mas o dominam. Exemplo disso é a questão da especulação com commodities, que faz com que os alimentos virem ativos. A comida entra na roda financeira como qualquer outro ativo e perde o status de alimento, de uso, passa a ser só um elemento de troca.

A inclusão de produtos agropecuários no mercado futuro de commodities foi feita inicialmente com o objetivo de responder à necessidade de cobertura de risco de preço, transferindo o risco da produção para agentes especuladores do mercado financeiro. O aumento do volume de capital especulativo e a decisão dos Estados nacionais de não mais investirem em estoques reguladores fez dos produtores rurais reféns dos preços estipulados pelos especuladores financeiros, que transformam definitivamente a comercialização de produtos agrícolas em um negócio, em 
A Agricultura a Partir do Neoliberalismo: Financeirização, Poder Corporativo e as Ameaças À Soberania Alimentar, pp. 42-58.

que a garantia de acesso da população aos alimentos é o que menos importa.

As consequências disso são conhecidas: frequentes períodos de carestia de alimentos; aumento da insegurança alimentar; mudança nas políticas de abastecimento dos países, como, por exemplo, o abandono da política de estocagem de produtos agrícolas, o que permitia a intervenção do Estado no controle do preço dos alimentos; revoltas populares etc.

O atrelamento da produção de alimentos ao sistema financeiro tornou-se maior na medida em que os governos reduziram a sua participação na regulação do mercado e eliminaram ou reduziram a importância das empresas responsáveis pela administração dos estoques reguladores (MARQUES, 2011). Esse fato, somado à inexistência de estoques reguladores, é responsável pelo aumento dos preços dos alimentos das últimas décadas, o que tem gerado as tantas crises alimentares pelo mundo. Não devemos negligenciar também o aumento no preço do petróleo como fator que estimulou o aumento do preço dos alimentos. No entanto, consideramos os primeiros dois fatores mais marcantes.

Sendo assim, se os países passam a priorizar a produção do que é mais interessante do ponto de vista dos mercados internacionais, e não do ponto de vista do consumo interno; se os países deixam de possuir estoques públicos que garantam a manutenção dos preços numa faixa viável tanto para consumidores como produtores; se permite-se que se especule com o preço dos alimentos no mercado financeiro, como é possível garantir que exista o acesso ao alimento por parte da população? Frente a isso, garantir a soberania alimentar significa garantir a regulação dos mercados e o investimento no mercado interno. Mais do que isso: significa a necessidade de impedir que o alimento entre na roda do mercado financeiro como simples ativo, posto que é algo essencial à vida. Sem isso, populações inteiras ficarão sempre à mercê do interesse de grupos econômicos que não possuem compromisso algum com a soberania alimentar. 
Outro aspecto importante desse regime e que se relaciona diretamente com tudo o que foi exposto até agora é a questão da mudança nos padrões alimentares, em especial na Ásia. O que vai marcar muito este nosso período é o aumento do consumo das carnes que vão, por sua vez, serem alimentadas com rações de soja ou milho. Trata-se da ocidentalização dos padrões alimentares com o aumento do consumo de carnes (bovina, suína e a de frango também). É importante lembrar que em muitas regiões isso significou uma melhora dos níveis nutricionais, mas em outras significou uma piora da qualidade nutricional ou a transformação na cultura alimentar.

Cabe agora refletir sobre como as grandes corporações conseguem colocar isso no mundo, isto é, impor os seus interesses para o mundo. Elas fazem isso de modo a expor seus interesses como sendo o interesse da sociedade.

Kneen (2002) descreve que uma das estratégias da Cargill é cultivar relações com todos os níveis de jurisdições políticas, de prefeitos a presidentes e primeiros-ministros. Ele afirma ainda que ela nunca foi tímida em toda a sua história em dizer aos governantes de qualquer nível, públicos ou privados, o que eles deveriam fazer. "Às vezes isso é vestido em termos de desenvolvimento econômico, às vezes em termos humanitários, e com frequência descaradamente como interesse próprio" (KNEEN, 2002:, p. 9, tradução nossa). Junto ao sistema de comercialização dos excedentes agrícolas do norte, ocorreu a proliferação da agroexportação dos países do sul, muitas vezes sob o mando das políticas de ajuste estrutural do FMI e do Banco Mundial em nome da máxima "alimentar o mundo" (MCMICHAEL, 2009a, p. 154).

Curiosamente essa é uma expressão central na missão da Cargill, descrita em seus sites oficiais e relatórios anuais. Um exemplo é o nome do relatório anual de 2012 sobre responsabilidade social da Cargill América Central: Nutriendo el futuro. O discurso político da Cargill é muito revelador de sua atuação. Kneen faz uma ampla pesquisa dos discursos de seus representantes em Invisible Giant. Transcrevo aqui dois fragmentos cujo argumento chama atenção. O primeiro é uma fala de Withney MacMillan, presidente da Cargill durante 18 anos (até 1995): 
É um erro acreditar que a maior necessidade da agricultura no mundo em desenvolvimento é desenvolver a capacidade de cultivar alimento para consumo local. Isso é um equívoco... Países devem produzir o que melhor produzem, e comercializá-lo... Agricultura de subsistência encoraja mal uso e danos ao meio ambiente (KNEEN, 2002, p. 10, tradução nossa).

Na mesma linha podemos ver a fala de seu vice-presidente Robbin Johnson:

Romper com o ciclo de pobreza significa mudar da agricultura de subsistência para a agricultura para comercialização. A agricultura de subsistência estanca o crescimento da renda dos camponeses; deixa populações fora do comércio de alimentos e portanto mais vulneráveis aos desastres nas safras, e prejudica o meio ambiente por meio do uso excessivo dos frágeis recursos naturais (Idem, p. 10 , tradução nossa).

Vemos que existe não apenas uma clara oposição à agricultura de subsistência, ou, como afirma Kneen (2002), a tudo o que represente uma alternativa a ser incorporado pelo sistema de dependência da Cargill, mas uma conotação pejorativa da agricultura camponesa ou, se preferirem, da pequena e média produção. Afinal, a subsistência permite que se sub exista. Ignora-se portanto que nas pequenas e médias propriedades é que se produz a maior parte dos alimentos consumidos no mundo e que nessa áreas que se emprega mais gente. No entanto, uma das estratégias da empresa foi e ainda é a de associar a sua imagem ao combate à fome. Frases como "ajudamos a alimentar o mundo" podem ser encontradas frequentemente em seus relatórios e folders corporativos. Nesse sentido, ela afirma que sua missão é prover de alimento o mundo e combater a fome e sustenta essa visão em dois argumentos principais:

- A produção e a distribuição local de alimento são vulneráveis às instabilidades das condições locais, que vão desde o clima, passando por pestes até desordem civil. 
- A maior produção agrícola alcançada por meio de economias de escala decorrentes da especialização de culturas específicas e métodos de alimentação animal mais eficientes pode tanto aumentar os rendimentos agrícolas como reduzir os preços ao consumidor.

Na fala de MacMillan notamos o uso dessa ideia:

Companhias como a Cargill [...] fazem coisas que vão ao coração do nosso problema da fome. Nós trazemos bens e serviços necessários à população para seu bem-estar. Nós criamos mercados que de outra forma poderiam não ser viáveis. Nós trazemos capital necessário e transferimos tecnologia e conhecimento que agregam eficiência ao mercado e transferimos os ganhos econômicos dessa eficiência agregada às pessoas das quais compramos e para as quais vendemos (KNEEN, 2002, p. 10, tradução nossa).

Historicamente a Cargill se utilizou desse discurso para ampliar a possibilidade de comercialização de grãos, como, por exemplo, a venda por meio do programa Food for Peace (mais conhecido como PL 480, de 1954). Segundo dados da ONG indiana Research Foundation for Science, Technology and Ecology, 7 dos 10 países que receberam essa ajuda ao longo das décadas de 1960 e 1970 tornaram-se 7 dos 10 melhores clientes para os grãos estadunidenses. Esse programa de ajuda minou a competição existente dos grãos nesses países, segundo a ONG (CORPORATE WATCH, 2001). Esse programa fez, de acordo com George (1978), com que o óleo de soja fosse introduzido em países que até então consumiam prioritariamente o óleo de oliva ou manteiga, como Espanha ou Tunísia.

Mais recentemente, na década de 1990, dada a óbvia incapacidade de os países industrializados reduzirem a fome tanto em seus próprios países como nos demais, a Cargill tem "reduzido sua elevada visão de alimentar o mundo para uma tarefa mais mundana de proporcionar soluções aos seus clientes..." (KNEEN, 2002 p. 14). Mas essas "soluções" não deixam de ter um papel estratégico para o desenvolvimento da empresa. A Cargill teve papel fundamental ao pressionar o governo dos Estados Unidos a retirar gradativamente os programas de apoio ao agricultor e implementar a lei conhecida como Freedom to Farm, cunhada 
A Agricultura a Partir do Neoliberalismo: Financeirização, Poder Corporativo e as Ameaças À Soberania Alimentar, pp. 42-58.

de Freedom to Fail por seus críticos. Essa lei, que retirava gradualmente os subsídios do governo mas deixava os produtores livres para decidirem o que e quanto produzirem, fez com que a Cargill pudesse comprar mais barato a produção dos agricultores ao mesmo tempo em que os deixou expostos às flutuações do mercado interno.

Segundo Araghi (2009), Daniel Amstutz, chefe executivo da Cargill, foi um participante importante das negociações do GATT, que mais tarde viria a se tornar a OMC (Organização Mundial do Comércio) com relação à elaboração dos acordos sobre a agricultura. Mais tarde, ele foi encarregado de redigir as políticas de agricultura e alimentação da constituição do Iraque. Segundo documento da Corporate Watch (2001), a Cargill tem um papel importante nos conselhos consultivos do governo dos Estados Unidos. Recentemente, a física indiana Vandana Shiva, conhecida militante contra os transgênicos, afirmou em entrevista que o vice-presidente da Cargill foi designado para escrever a lei de comércio e agricultura dos Estados Unidos. Dave Ostendorf, diretor de um grupo que defende o direito dos produtores rurais de Iowa, afirmou que não há dúvida de que durante a administração Reagan, a Cargill foi chamada para dar "pitacos", tanto na política agrícola nacional como na internacional. E completou dizendo que muitos dos funcionários do Departamento de Agricultura dos Estados Unidos (USDA) e até mesmo membros do Congresso estão "no bolso da Cargill" (AHLBERG, 1988).

O que é importante destacar aqui é o papel que corporações como a Cargill possuem no desenho de um sistema global de circulação e troca de valor. Como esclarece Araghi (2009), o GATT, instância na qual a Cargill esteve tão presente, pode ser entendido como um acordo entre os Estados Unidos e a Europa para resolver suas crises de superprodução, fazendo do sul global seu mercado para escoar excedentes por meio de dumping.

Diante desse quadro, pensar na soberania alimentar significa inevitavelmente pensar em fazer frente a esse poder corporativo e devolver ao Estado o seu papel regulador. O que se produz, como se produz e por quem é produzido não pode ser definição puramente de mercado. Para tal, 
é preciso vencer o lobby dos grandes grupos e garantir a participação ampla e plural na definição das políticas públicas do setor alimentar.

\section{Referências bibliográficas}

AHLBERG, B. Cargill: the invisible giant, Multinational Monitor, 1988. Disponível em: <http://www.multinationalmonitor.org/hyper/issues/1988/07/mm0788_09. html>. Acesso em: 13 set. 2013.

ARAGHI, F. Food regimes and the production of value: some methodological issues, The Journal of Peasant Studies, Essex, 30(2), p. 41-70, 2001.

CASTRO, A. C. Competitividade da indústria de óleos vegetais. In: $M C T / F I N E P / P A D C T$, Estudo da competitividade da indústria brasileira. Campinas: Editora Mimeo, 1993.

CHESNAIS, F. A mundialização financeira: gênese, custos e riscos. São Paulo: Xamã, 1999.

A Mundialização do Capital. São Paulo: Xamã, 1996.

CORPORATE WATCH. GE briefing serires: Cargill Arrogance Incorporated. 2001. Disponível em: <http://www.corporatewatch.org> Acesso em: 22 out. 2011.

DELGADO, G. C. Capital financeiro e agricultura no Brasil: 1965-1985. Campinas: Editora Ícone, 1985.

FRIEDMANN, H. From colonialism to green capitalism: social movements and the emergence of food regimes. In: Buttel F. H.; McMichael, P. (Eds.). New directions in the sociology of global development. Research in rural sociology and development, Vol. 11. Oxford: Elsevier, 2005. p. 22967.

GEORGE, S. 0 mercado da fome. Rio de Janeiro: Paz e Terra, 1978.

GOWAN, P. A roleta global. Rio de Janeiro, Record, 2003.

HARVEY, D. O neoliberalismo: história e implicações. São Paulo: Edições Loyola, 2011.

MARTINELLI JÚNIOR, O. As tendências mundiais recentes da indústria processadora de alimentos. Revista Pesquisa \& Debate, v. 10, n. 1(15), p. 5-40, 1999.

KNEEN, B. Invisible Giant. Cargill and its transnational strategies. Londres: Pluto Press, 2002.

LLAMBÍ, L. Reestruturaciones Mundiales de la Agricultura y la Alimentación. El papel de las transnacionales y los grandes estados. Revista

Agroalimentária, n. 1, set. 1995. Disponível em:

<http://erevistas.saber.ula.ve/index.php/agroalimentaria/article/view/1152 /1106>. Acesso em: 30 out. 2011 
A Agricultura a Partir do Neoliberalismo: Financeirização, Poder Corporativo e as Ameaças À Soberania Alimentar, pp. 42-58.

MARQUES, M. I. M. O novo significado da questão agrária. Anais ENANPEGE. 2011.

MAZZALI, L. O processo recente de reorganização agroindustrial: do complexo à organização "em rede". São Paulo: Editora Unesp, 2000.

MCMICHAEL, P. A food regime genealogy. Journal of Peasant Studies, 36: 1, 2009a.

A food regime analysis of the "world food crisis". Agric Hum Values, 26:281-295, 2009b.

PAULANI, L. A autonomização das formas verdadeiramente sociais na teoria de Marx: comentários sobre o dinheiro no capitalismo contemporâneo.

Revista ANPEC: Encontro Nacional de Economia, Foz do Iguaçu, dez. 2009 Disponível em: <www.anpec.org.br/encontro_2009>. Acesso em: nov. 2011.

PLOEG, J. D. V. Camponeses e impérios alimentares: lutas por autonomia e sustentabilidade na era da globalização. Porto Alegre: Editora UFRGS, 2008.

REVISTA CARGILL. São Paulo, n. 27, ano 31, jun./jul. 2011.

ROBERTS, P. 0 fim dos alimentos. Rio de Janeiro: Elsevier, 2009.

' A escolha da Cargill se deve ao fato de ter sido objeto da pesquisa de doutorado da autora. 